\title{
The analysis of investment into industries based on portfolio managers
}

\author{
Henrieta PAVOLOVÁ, Tomáš BAKALÁR ${ }^{1 *}$, Kamil KYŠEL' ${ }^{1}$, Miroslav KLIMEK', \\ Zuzana HAJDUOV $A^{2}$ and Marcin ZAWADA ${ }^{3}$
}

Authors' affiliations and addresses:

${ }^{1}$ Technical University of Košice, Faculty of

Mining, Ecology, Process Control and

Geotechnologies, Letná 9, 04200 Košice,

Slovakia

e-mail: henrieta.pavolova@tuke.sk

e-mail: tomas.bakalar@tuke.sk

e-mail:kamil.kysela@tuke.sk

${ }^{2}$ University of Economics in Bratislava, Faculty of Business Management, Dolnozemská cesta 1, 85235 Bratislava, Slovakia

e-mail: miroslavklimek@zoznam.sk

e-mail: zuzana.hajduova@euba.sk

${ }^{3}$ Częstochowa University of Technology, Faculty of Management, Dąbrowskiego 69, 42-200

Częstochowa, Poland

e-mail: marcinzawada04@gmail.com

\section{*Correspondence:}

Tomáš Bakalár, Technical University of Košice, Faculty of Mining, Ecology, Process Control and Geotechnologies, Letná 9, 042 00, Košice,

Slovakia

tel: +421556022974

e-mail: tomas.bakalar@tuke.sk

Funding information:

This research was funded by MŠVVaŠ SR

Grant Number VEGA 1/0240/20

How to cite this article:

Pavolová, P., Bakalár, T., Kyšel'a, K., Klimek,

M., Hajduová, Z. and Zawada, M. (2021). The

analysis of investment into industries based

on portfolio managers. Acta Montanistica

Slovaca. Volume 26 (1) 161-170

DOI:

https://doi.org/10.46544/AMS.v26i1.14

\begin{abstract}
The main goal of each investor when investing capital is to recover funds. The current market brings unlimited opportunities in creating an investment strategy. This strategy is highly dependent on the investor's preferences, his attitude to risk, financial capacity, expected return, self-interest, and many other factors that determine what is best for the investor. For this reason, the submitted work concerns investors who will comply with strict restrictions. In this way, an investment strategy for a selected group of investors can be created. The paper focuses on investors in Slovakia. The art of investment decisions to make the greatest possible return is portfolio management. The studies presented in this work are designed to explore different models and to achieve investor goals to maximise their investment and minimise risk.

Investing is a systematic and long-term process where the investor gives up part of his free funds to increase their value and collect the return for them in the future. Investing is effective only if it follows certain rules. Sending a monthly deposit with iron regularity is, in the event of a recession and crisis, the only guarantee of achieving the desired future goal of investing.

Mutual funds are a simple way of collective investment, where a person collects money from investors and invests in various assets such as stocks, government bonds, currencies, commodities. Profits from the investment are distributed to all investors who contributed to the fund. These funds are professionally managed by investment specialists based on their market knowledge. A share is equity security representing an equity interest in a joint-stock company. Monetary policy and financial stress significantly affect the ability of the actively managed fund's performance vis-a-vis ETFs performance. This fact must be stated as this is a limitation of the analysis in the presented paper.
\end{abstract}

\section{Keywords}

Investment, investment strategy, mining, mining industry, comparison of investment instruments, fund, investor 


\section{Introduction}

The global mining industry faces many challenges and risks: a moderate commodity market, costmanagement challenges, access to finance and growing expectations for social, economic, and environmental participation within the host society and regulators. At the same time, investors demand operational rigour and capital discipline to ensure an appropriate return on assets and capital-intensive projects. For mining companies, the steady decline in average commodity prices from year to year maintains the pressure to minimise all overhead costs. However, in industries where losses are not many but significant, Marsh's mining approach helps large and small companies prevent, manage and transfer risk throughout the mining cycle, from capital gains to mine closures.

This research tries to create an investment strategy for a selected group of investors. The result is the creation of equity portfolios. The first basic step is to find out whether it makes sense to seek portfolio titles that can overcome the benchmark actively, or it is more appropriate to choose a passive approach, given the modesty in favour of this strategy.

The next step is to select the appropriate investment instrument. The authors of the paper assume that the most suitable option will be mutual funds or ETF-traded funds. The goal is to evaluate the investment options and to identify the advantages and disadvantages of a fund choice. This is much more than selecting individual titles for a portfolio or hedge funds, but in terms of the nature of the costs, these options assume that they will not fit the selected profile (Abner, 2010; Bonin, 2005).

The authors use these methods to compare investment approaches and tools. The work should result in a complete guide for investors that meets the constraints to create the most appropriate strategy for the investor. There are several studies in the literature available that deal with mutual funds. Some of these studies deal with collective investment issues (Anderson, 2010; Ferri, 2009), some of them dealing with issues of investing in different assets (Boyd, 2010), government bonds, currency (Broyden, 1970) or different commodities (Evans, 2010; Fama, 2012). The authors of the study ( Haslem, 2010; Frdson, 2002) analysed the profits of investments managed by investment specialists. Another study (Lerman, 2002; Hendrych, 2019) looked at the effectiveness of investing in funds within one day, depending on the type of fund.

Other authors (Hamilton, 2012; Marfatia, 2014, 2015) have focused more on reducing the risk of investing and in another study (Mačí, 2017; Faust, 2003) on income capital. In the same period, investment in the funds was also examined by the public, as well as in studies (Paiardini, 2014; Sun, 2017), and it was found that a conservative investor prefers monthly investments. They also found it important to look for a suitable investment tool. In a further study (Sarwar, 2017; Svitálková, 2014), mutual funds and ways of investing in them were analysed. Many studies indicated that precise forecasts of bond yields and excess returns can use ETF (Poterba, 2002).

Mutual funds are a simple way of collective investment, where a person (organisation) collects money from investors and invests in various assets such as stocks, government bonds, currencies, commodities. Profits from the investment are distributed to all investors who contributed to the fund. These funds are professionally managed by investment specialists based on their market knowledge. Funds can be purchased at a specific date or at any time during business hours, depending on the type of fund in which they are invested. Capital market investment is primarily related to the concept of action (Wong, 1997; Zhang, 2019).

A share is equity security representing an equity interest in a joint-stock company. It is, therefore, an instrument offering the possibility of achieving a great profit, but of course, also a risk of achieving a significant loss. No doubt profit is the most obvious reason why investors are trying to find and buy companies' shares that should bring them interesting evaluation. Of course, investors are trying to eliminate the risk of the investment as much as possible, but without losing the revenue potential (Vychytilová, 2015; Wright, 2012).

Monetary policy and financial stress significantly affect the ability of the actively managed fund's performance vis-a-vis ETFs performance. Because of that fact, the authors need to state this as a limitation of the paper. The following related studies that highlight this point are referred to:

(a) Marfatia, H.A., 2014. Impact of uncertainty on the high-frequency response of the US stock markets to the Fed's policy surprises. The Quarterly Review of Economics and Finance, 54(3), pp. 382-392.

(b) Marfatia, H.A., 2015. Monetary policy's time-varying impact on the US bond markets: Role of financial stress and risks. The North American Journal of Economics and Finance, 34, pp. 103-123.

(c) Sarwar, G. and Khan, W., 2017. The effect of US stock market uncertainty on emerging market returns. Emerging Markets Finance and Trade, 53(8), pp. 1796-1811. 


\section{Material and Methods}

When verifying the effectiveness of active investment management, available data from actively managed mutual funds are used. This paper used the data available to one of the most successful fund managers in the history of franklintempleton.com. When verifying the most successful funds in the Slovak Republic, the authors must manually implement a suitable benchmark because they do not mention these benchmark funds. The authors will build on the description and characteristics of the fund. In this paper, we used the ranking on https://openiazoch.zoznam.sk/podiel-fondy/rebricky to find the most successful funds in Slovakia. For index searches, we used data from individual exchanges www.nyse.com, www.nasdaq.com and the like.

When comparing the ETF's fee benefits, mutual funds and title collection is used the fees of the oldest and most trusted ETF providers, Vanguard.com and IShares.com. It is needed to know the broker's fees when estimating ETF fees and solo titles. These can be found by a simple survey among the options for a Slovak user. Using quantile analysis, the fund size, investment strategy, denomination, fund information policy can be tracked. In this comprehensive analysis, the hidden risks and factors that influence the creation of the right investment strategy can be identified.

Investments in these portfolios may not only be the privilege of "professional" investors. It can also meet with the "lay" public, especially in the form of investing in so-called mutual funds. The profile investor is a conservative investor who prefers to invest in shares over 15 years on a regular monthly basis with an investment of $€ 200$ per month to $€ 5,000$ per month.

Regarding the quantitative focus of the research, primary quantitative methods of investigation and mathematical-statistical methods will be used.

Quantitative indicators for the evaluation of funds:

$$
R=N A V_{i+1} /\left(N A V_{i}-D_{i}\right)-1
$$

where:

$R$ - fund performance - the absolute performance of the fund or the appreciation for the unitholder over a given period,

$N A V_{i}$ - NAV per share or share valid on the last day of the dividend entitlement (not yet reduced by dividend), where $N A V_{0}$ is NAV at the beginning of the period, and $N A V_{i+1}$ is NAV at the end of the period,

$D_{i}$ - the amount of dividend per share or share, where $D_{0}=0$,

$n$ - number of dividends in the given time,

$i$ - dividend serial number (index).

When evaluating the performance of mutual funds, it is necessary to draw attention to the problem of annualisation, i.e. mechanical recalculation of fund performance over a short period of time to an annual period. The absolute performance of the fund may be annualised according to the formula, and the symbol "p.a." shall be added after the calculated result.

Ratio-indicator gives information on the fund performance against the benchmark considering the risk, and the higher the number, the better done. If the result is a negative number, the fund manager managed inefficiently compared to the benchmark.

$$
I R=(R-R m) / \text { Tracking error }
$$

where:

$I R$ - Information ratio - indicator

$R$ - fund performance (\%),

$R m$ - market performance.

Tracking error - annualised standard deviation of the difference between the fund's annual performance and the benchmark

Sharp ratio - the original Sharp indicator compares the fund's performance to the risk-free return. The calculation and comparison of the performance of the fund were simplified with the performance of the index. In this way, the necessary result is found, and if the result is a positive number, the fund performed better than the index. If the number is negative, the fund manager was inefficient.

$$
S R=\left(R-R_{f}\right) / s m
$$

where:

$S R$ - Sharp indicator

$R_{f}$ - index performance (\%),

$s m$ - annualised standard deviation of the fund's annual performance (\%). 
The fee requirements of individual investments in ETFs and mutual funds are compared. For this purpose, the MS Excel program is used, where a formula for calculating the investment development in the ETF and a formula for calculating the investment development in mutual funds for regular deposits are created. For this purpose, average interest over the entire period invested is used. In the calculations, the basic compound interest formula was used:

$$
S=S_{0} *(1+P / 100 \%)^{n}
$$

where:

$S$ - the resulting amount of interest,

$S_{0}$ - principal, i.e. the initial amount required,

$P$ - interest rate, percentage of the principal for the interest period,

$n$-number of years to borrow.

Since the investment will run monthly for a higher calculation accuracy in the first year of the invested amount, the interest for each deposit is calculated separately:

$$
P=[1+(12 / 12 p) / 100+1+(11 / 12 p) / 100+\ldots+1+(1 / 12 p) / 100] / 12 q(5)
$$

In addition, fees that differ for mutual and ETF funds must be included in the calculation:

$$
\text { Mutual Funds: } S_{1 \text { styear }}=\left(S_{0}-\text { entry fee }\right) *\left(1+p_{1 \text { styear }}\right) / 100 \%
$$

The result with compound interest and increase the number of years until the end of the investment is calculated.

$$
S_{y}=S_{1 \text { styear }} *(1+p / 100 \%-\text { management fee })
$$
is made:

This procedure is repeated with each investment for the duration of the investment and then the sum of all $\mathrm{S}$

$$
\begin{aligned}
& S_{\text {sum }}=S_{y}+S_{y+1}+S_{y+2}+\ldots+S_{y+x} \\
& S=S_{\text {sum }}-S_{\text {sum }} * \text { output fee }
\end{aligned}
$$

ETF:

$$
S_{\text {lstyear }}=\left(S_{0}-\text { entry fee }\right) *\left(1+p_{1 \text { styear }}\right) / 100 \%-\text { management fee }
$$

The entry fee is calculated as follows:

$$
\text { Entry fee }=\text { number of open positions } \times \text { entry fee for the opening position }
$$

\section{Results}

To compare investment approaches and make the right choice for the investor profile, the success of actively managed investments must be measured. Because the investor profile predetermines to choose only from collective forms of investing, the success of active mutual fund managers must be investigated. In order to do this, the Sharp indicators and the information ratio will help in considering both the risk and the manager's yield compared to the index. In order to be able to say that the manager was successful, he should achieve positive numbers in both cases. From the analysis, the results are most favourable for administrators. During this period, 40 funds were analysed in terms of performance and 12 of them managed to overcome their benchmark, the index to which they were linked. However, if the management fee of these funds is relied on, only 3 funds outperformed the performance benchmark. It is a clear sign of the way the fees burden the investments. The worst part of the fee was the funds in the longest common reference period, where neither the benchmark with the fee was overcome, but at least the funds were analysed. 


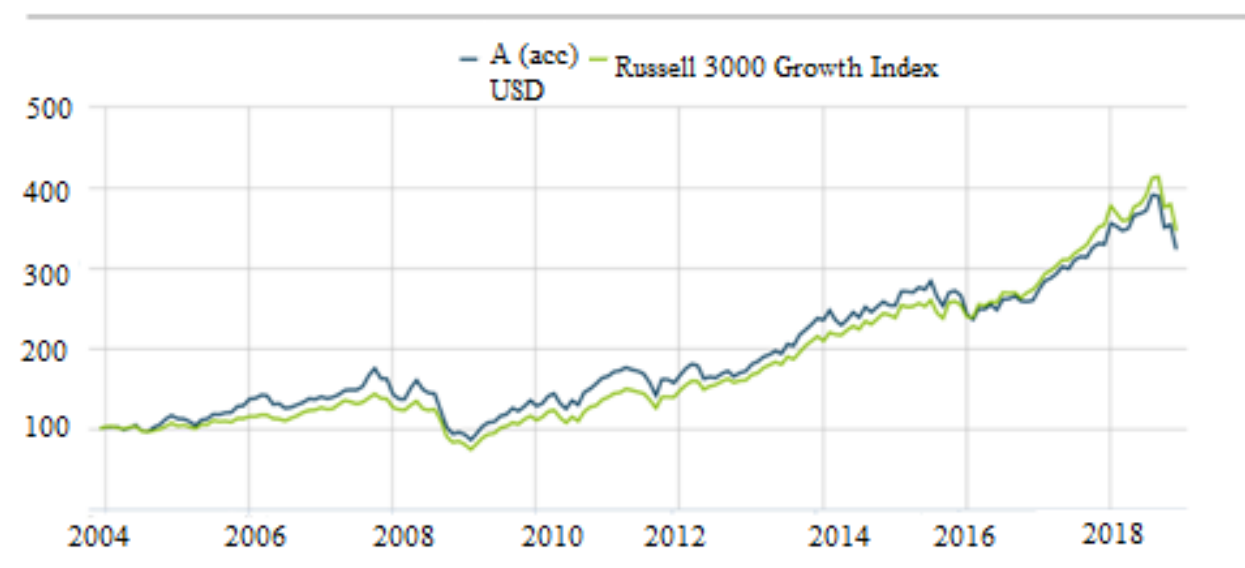

Fig. 1. Franklin U.S. Performance Opportunities vs Russell 3000 Growth Index.

Franklin Templeton shares are lagging the benchmark from $-1.08 \%$ to $-1.99 \%$ in terms of stock performance but lagged from $-3.11 \%$ to $-3.99 \%$ with the fee. All funds were tracked together with 33 that would perform for calculation for each year for 8 years. A total of 28 of the 33 Franklin Templeton Equity Funds could not overcome the benchmark for the information ratio and the Sharp ratio. If talking about a percentage, $85 \%$ of the funds could not overcome the benchmark. Since the beta result and volatility in mutual funds are not positive, only the performance of these funds is compared to the benchmark, especially for the calculation of the management fee, which is calculated annually from the total value of the client's fund. Only 6 funds out of 100 managed to overcome their benchmark in terms of the information ratio. Another 3 funds managed to reach 0 in terms of the information ratio. This suggests that the same results as the benchmark in terms of risk and performance would be achieved. When comparing funds using Sharp's ratio, only 5 funds out of 100 succeeded in overcoming the benchmark, and four more funds reached 0 . The funds were charged with management fees from $1.5 \%$ to $2.1 \%$ per year of the total assets, while no link between the fee level and the fund's success was found. These results only support the arguments and research of recent years that active management is wiping out investors with a significant amount of money and unduly because active management fails in most cases.

\begin{tabular}{|c|c|c|c|c|c|c|}
\hline & Beta & $\begin{array}{l}\text { Info. } \\
\text { Ratio }\end{array}$ & $\begin{array}{c}\text { Sharp } \\
\text { ratio }\end{array}$ & $\begin{array}{l}\text { Management } \\
\text { fee }\end{array}$ & $\begin{array}{c}\text { Tracking } \\
\text { error }\end{array}$ & $\begin{array}{l}\text { Standard } \\
\text { deviation }\end{array}$ \\
\hline IAD - Global Index & & -0.08 & -0.60 & $3.54 \%$ & & 21.57 \\
\hline MSCI World Index & 0.94 & & & & 11.11 & 24.34 \\
\hline Amundi Funds II - Pioneer Global Select EUR & & -0.17 & -0.74 & $1.80 \%$ & & 25.87 \\
\hline MSCI World Index & 0.85 & & & & 14.81 & 20.84 \\
\hline TAM - American Stock & & -1.00 & -0.15 & $1.80 \%$ & & 24.80 \\
\hline S\&P 500 Index & 1.31 & & & & 3.20 & 34.34 \\
\hline Amundi Funds II -Emerg. Markets Equity EUR & & -0.27 & -0.50 & $1.50 \%$ & & 26.75 \\
\hline MSCI Emerging Markets Index & 0.99 & & & & 10.77 & 26.28 \\
\hline TAM - European Stock & & -0.01 & -0.07 & $2.10 \%$ & & 31.78 \\
\hline MSCI Europe Index & 1.10 & & & & 3.92 & 27.08 \\
\hline AXA Selection Global Equity & & -0.04 & 0.11 & $1.80 \%$ & & 25.98 \\
\hline MSCI World Index & 0.99 & & & & 5.15 & 24.39 \\
\hline Amundi Funds II - U.S. Pioneer Fund EUR & & -0.05 & -0.86 & $1.60 \%$ & & 26.35 \\
\hline S\&P 500 Index & 0.95 & & & & 10.87 & 24.98 \\
\hline Amundi Funds II -European Equity Targe Income EUR (DSA) & & -0.03 & -0.03 & $3.54 \%$ & & 35.28 \\
\hline MSCI Europe Index & 0.94 & & & & 9.73 & 31.24 \\
\hline Amundi S.F. - European Equity Optimal Volatility EUR & & -0.06 & -0.44 & $3.54 \%$ & & 22.89 \\
\hline MSCI Europe Index & 0.85 & & & & 3.24 & 21.49 \\
\hline TAM - NewMarkets open-end mutual fund & & -0.05 & -0.27 & $1.80 \%$ & & 31.24 \\
\hline MSCI Emerging Markets Index & 1.31 & & & & 10.97 & 22.89 \\
\hline Amundi S.F. - European Equity Target Income EUR (DQ) & & -0.03 & -0.08 & $1.80 \%$ & & 21.49 \\
\hline MSCI World Index & 0.99 & & & & 5.76 & 36.90 \\
\hline AXA CEE Equity & & -0.18 & -0.17 & $1.50 \%$ & & 31.20 \\
\hline MSCI Europe Index & 1.10 & & & & 7.40 & 30.60 \\
\hline AM SLSP Global Equity & & -0.24 & -1.00 & $2.10 \%$ & & 25.78 \\
\hline MSCI World Index & 0.98 & & & & 5.53 & 24.14 \\
\hline AXA Selection Emerging Equity & & -0.15 & -0.27 & $1.80 \%$ & & 26.58 \\
\hline MSCI Emerging Markets Index & 1.13 & & & & 4.56 & 27.47 \\
\hline ESPA Stock Global & & -0.54 & -0.01 & $1.60 \%$ & & 24.98 \\
\hline MSCI World Index & 1.26 & & & & 10.82 & 32.58 \\
\hline Fidelity Funds - Global Dividend Fund A-ACC-EUR (hedged) & & -0.01 & -0.04 & $3.54 \%$ & & 31.24 \\
\hline MSCI World Index & 1.00 & & & & 9.25 & 30.25 \\
\hline Amundi Funds II - Pioneer U.S. Fundamental Growth EUR & & -0.10 & -0.05 & $1.50 \%$ & & 32.14 \\
\hline S\&P 500 Index & 1.02 & & & & 5.69 & 26.35 \\
\hline
\end{tabular}




\begin{tabular}{|c|c|c|c|c|c|c|}
\hline Amundi Funds II - European Equity Target Income EUR (ND) & & -0.12 & -0.03 & $2.10 \%$ & & 24.98 \\
\hline MSCI Europe Index & 0.74 & & & & 7.36 & 32.58 \\
\hline Fidelity Funds - Latin Am. Fund A-DIST-USD & & 0.00 & -0.06 & $1.80 \%$ & & 31.24 \\
\hline MSCI EM Latin America Index & 1.01 & & & & 7.28 & 22.89 \\
\hline ESPA Stock Global Emerging Markets & & -0.42 & -0.16 & $1.60 \%$ & & 21.49 \\
\hline MSCI Emerging Markets Index & 0.95 & & & & 4.05 & 36.55 \\
\hline Templeton Emerging Markets Fund & & -0.13 & -0.12 & $3.54 \%$ & & 36.14 \\
\hline MSCI Emerging Markets Index & 1.07 & & & & 6.91 & 25.47 \\
\hline Amundi Funds II - Gl. Equity Target Income EUR & & 0.00 & -0.20 & $2.10 \%$ & & 26.80 \\
\hline MSCI World Index & 1.23 & & & & 5.83 & 27.80 \\
\hline Amundi Funds II - Global Ecology EUR & & -0.16 & -0.18 & $1.80 \%$ & & 30.90 \\
\hline MSCI World Index & 1.00 & & & & 7.24 & 25.90 \\
\hline ČSOB Global Equity & & -0.30 & -0.10 & $1.60 \%$ & & 27.00 \\
\hline MSCI World Index & 0.92 & & & & 4.05 & 35.30 \\
\hline
\end{tabular}

Tab. 2. Mutual fund.

\begin{tabular}{c|c}
\multicolumn{2}{c}{ Tab. 2. Mutual fund. } \\
\hline \multicolumn{2}{c}{ Mutual fund 12 deposits/year } \\
\hline Monthly invested amount & $215 \$$ \\
Average annual recovery & $7.5 \%$ \\
Management fee & $1.5 \%$ \\
Entry fee & $0.0 \%$ \\
Exit fee & $0.0 \%$ \\
\hline
\end{tabular}

The chart in Fig. 1 shows Franklin U.S. performance Opp. compared to the Russell 3000 Growth Index benchmark, which lagged by $2.06 \%$ without adding annual fund management fees. The Sharp ratio of this fund is -0.08 . The information ratio of this fund is -0.39 . Fund of the most important assets of the developed US market does not overcome the index and lags performance and risk.

Tab. 3. ETF.

\begin{tabular}{c|c}
\hline \multicolumn{2}{c}{ Eab. 3. ETF. } \\
\hline ETF fund 12 deposits/year & $208 \$$ \\
\hline Invested amount without the fees & $7.5 \%$ \\
Average annual recovery & $0.05 \%$ \\
Management fee & $7.95 \$$ \\
Entry fee to a broker & $7.95 \$$ \\
Exit fee to a broker & $216 \$$ \\
Regularly invested amount & $208 \$$ \\
Price of 1 fund share & 1 \\
Purchased shares & $0.01 \%$ \\
Bid / Ask spread &
\end{tabular}

Tab. 4. Mutual fund withdrawals [\$].

\begin{tabular}{l|r} 
State on account after 1st year & 2658 \\
Withdrawal after 5th year & 14995 \\
Withdrawal after 6th year & 18558 \\
Withdrawal after 7th year & 22335 \\
Withdrawal after 8th year & 26340 \\
Withdrawal after 9th year & 30587 \\
Withdrawal after 10th year & 35090 \\
Withdrawal after 11th year & 39865 \\
Withdrawal after 12th year & 44927 \\
Withdrawal after 13th year & 50294 \\
Withdrawal after 14th year & 55986 \\
Withdrawal after 15th year & 62020 \\
Withdrawal after 16th year & 68418 \\
Withdrawal after 17th year & 75202 \\
Withdrawal after 18th year & 82396
\end{tabular}




\begin{tabular}{l|c} 
Withdrawal after 19th year & 90023 \\
Withdrawal after 20th year & 98109 \\
Withdrawal after 21st year & 106684 \\
Withdrawal after 22nd year & 115775 \\
Withdrawal after 23rd year & 125415 \\
Withdrawal after 24th year & 135636 \\
Withdrawal after 25th year & 146473 \\
Withdrawal after 26th year & 157964 \\
Withdrawal after 27th year & 170148 \\
Withdrawal after 28th year & 183066 \\
Withdrawal after 29th year & 196764 \\
Withdrawal after 30th year & 211287 \\
Withdrawal after 31st year & 226686 \\
Withdrawal after 32nd year & 243014 \\
Withdrawal after 33rd year & 260326 \\
Withdrawal after 34th year & 278682 \\
Withdrawal after 35th year & 298145
\end{tabular}

Tab. 1 shows the actively managed mutual funds with the largest volume of capital in Slovakia according to the ranking seznam.openiazoch.sk. In the 15-year period, the funds in terms of performance and risk using the information and Sharp ratio were evaluated.

Only 6 funds out of 100 managed to overcome their benchmark in terms of the information ratio. Another 3 funds managed to reach 0 in terms of the information ratio. This suggests that the same results would be achieved as the benchmark in terms of risk and performance.

When comparing funds using Sharp's ratio, only 5 funds out of 100 succeeded in overcoming the benchmark, and four more funds reached 0 .

The funds were charged with management fees from $1.5 \%$ to $2.1 \%$ per year of the total assets, while no link between the fee level and the fund's success was found. These results only support the arguments and research of recent years that active management is wiping out investors with a significant amount of money and unduly because active management fails in most cases.

The investor profile is only in collective investment because it only makes sense to the budget. The question of the investment approach has been answered, and the question of the investment instrument is coming up. Here, after analysing the current state of the problem, 2 investment instruments are appropriate. Mutual Fund and ETF (Tab. 2).

\begin{tabular}{c|c} 
Tab. 5. ETF withdrawals [\$]. & \\
State on account after 1st year & 2597 \\
Withdrawal after 5th year & 14597 \\
Withdrawal after 6th year & 18226 \\
Withdrawal after 7th year & 22133 \\
Withdrawal after 8th year & 26339 \\
Withdrawal after 9th year & 30867 \\
Withdrawal after 10th year & 35741 \\
Withdrawal after 11th year & 40987 \\
Withdrawal after 12th year & 46632 \\
Withdrawal after 13th year & 52707 \\
Withdrawal after 14th year & 59243 \\
Withdrawal after 15th year & 66275 \\
Withdrawal after 16th year & 73840 \\
Withdrawal after 17th year & 81979 \\
Withdrawal after 18th year & 90733 \\
Withdrawal after 19th year & 100149
\end{tabular}




\begin{tabular}{l|l} 
Withdrawal after 20th year & 110277 \\
Withdrawal after 21st year & 121169 \\
Withdrawal after 22nd year & 132883 \\
Withdrawal after 23rd year & 145481 \\
Withdrawal after 24th year & 159028 \\
Withdrawal after 25th year & 173595 \\
Withdrawal after 26th year & 189260 \\
Withdrawal after 27th year & 206103 \\
Withdrawal after 28th year & 224213 \\
Withdrawal after 29th year & 243684 \\
Withdrawal after 30th year & 264620 \\
Withdrawal after 31st year & 287128 \\
Withdrawal after 32nd year & 311328 \\
Withdrawal after 33rd year & 337344 \\
Withdrawal after 34th year & 365314 \\
Withdrawal after 35th year & 395383
\end{tabular}

In the first comparison, there is a mutual fund in which the lowest management fee of $1.5 \%$ was entered from the list. Although active managed funds are unable to achieve the same benchmark performance benchmarking, identical performance to ETFs and mutual funds according to the historical performance of the 500 largest US companies was given over the past 30 years. At the \$215 entered, the ETF withdrawal against the mutual fund will only pay off after 9 years of investment, but then the ETF investment is significantly faster than in the mutual fund (Tab. 3).

In the article, the index share fund and the index ETF in Tab. 4 and Tab. 5 shows the results of this comparison were compared. In the discussion, what would happen with the investment if it were done on a regular basis, but not every month, only every 2 months, or every 3 months is presented. In this way, a significant amount on fees can be saved, which is due to the nature of ETF fees, where a fixed amount when entering the store is paid. In mutual funds, this is not possible and would not make sense in terms of fees.

\section{Discussion}

Declines or falls on stock exchanges are quite common. If it is a drop above $10 \%$, it is a correction in the stock markets. It occurs in about every second quarter, so it is quite common. The currently spreading coronavirus caused a market correction. Stock exchanges have fallen by about $12 \%$ so far. However, the fall was relatively fast, and experience showed that the faster the fall, the faster the increase. And in the case of the current situation, it can be assumed that it will be the same. In this situation, investing by companies is very complicated due to the COVI-19 pandemic. Coronavirus has changed the world and affected globalisation for decades to come. Based on an analysis by world meters, the number of infected in each state is known from the beginning of the pandemic to the present. In the following graphs, an increase in infected and deceased people who were positive for Covid-19 can be observed in the daily increment of infected from 22.1.2020 to 2.6.2020. From the graph, the pandemic has gained the greatest strength of the number of infected at the end of May to the present. The biggest jump occurred during March. This phenomenon also significantly affected the behaviour of investors in the financial markets.

The VIX index is a measure of market volatility. Its value is derived from the implicit volatility of options on the S\&P 500 index. The calculation includes call and put options that have 23 to 37 days until expiration. On average, it is an option with a 30-day expiration; whose implied volatility serves as the basis for calculating the value of VIX. It can be shown how nervous the markets were during the pandemic by the graph in Fig. 2, which shows the historical volatility of the VIX index during the 6-month period in the Covid-19 pandemic. The continuity and strong direct correlation between the volatility (the nervousness of the stock market) with the previous charts can be noticed. This phenomenon is understandable because investors are responding to the current pandemic as a threat to their investment. Many segments in which listed companies operate were negatively affected by the pandemic, with declining sales and profits. Of course, the pandemic emergency was not considered when predicting future developments. This means that most companies have not been able to meet the expectations of investors, and even worse, some companies have not kept a sufficient financial reserve and are dependent on state aid and are in danger of bankruptcy. 
From the volatility chart, the biggest panic in the markets was in March, when the numbers of infected and dead on Covid-19 also rose sharply. As soon as the daily increase in infected and dead people stabilised and did not increase exponentially, the VIX index fell sharply.

The chart in Fig. 3 shows the index of the largest 500 US companies traded on the stock exchange. The index includes 500 leading companies and covers approximately $80 \%$ of the available market capitalisation with the three largest companies, Apple, Microsoft, and Exxon. Like all other key indicators, the S\&P 500 uses the Global Industry Classification Standard (GICS) to divide companies into industries such as energy, healthcare, finance, information technology and retail. The index has existed since 1923, but in January 1957, it was expanded to 500 companies. The chart of the index performance over time gives an overview of the highest and lowest levels of the US economy during periods of growth and recession.

In Fig. 3, the trend of this index in the key period of the pandemic to the present is shown. It can be clearly seen the way the development of the index indirectly correlates with the number of infected and volatility in the markets. This means that investors flocked to their positions in these companies and moved to other assets or held cash. A sharp decline and subsequent steep growth can be noticed, and even here, it can be noticed how strongly the psyche and elderly influence the behaviour of investors. In the key period from March to May, daily fluctuations were in the tens of per cent in both directions, causing various new information and misinformation, which investors analysed and subsequently tried to profit from the market slump.

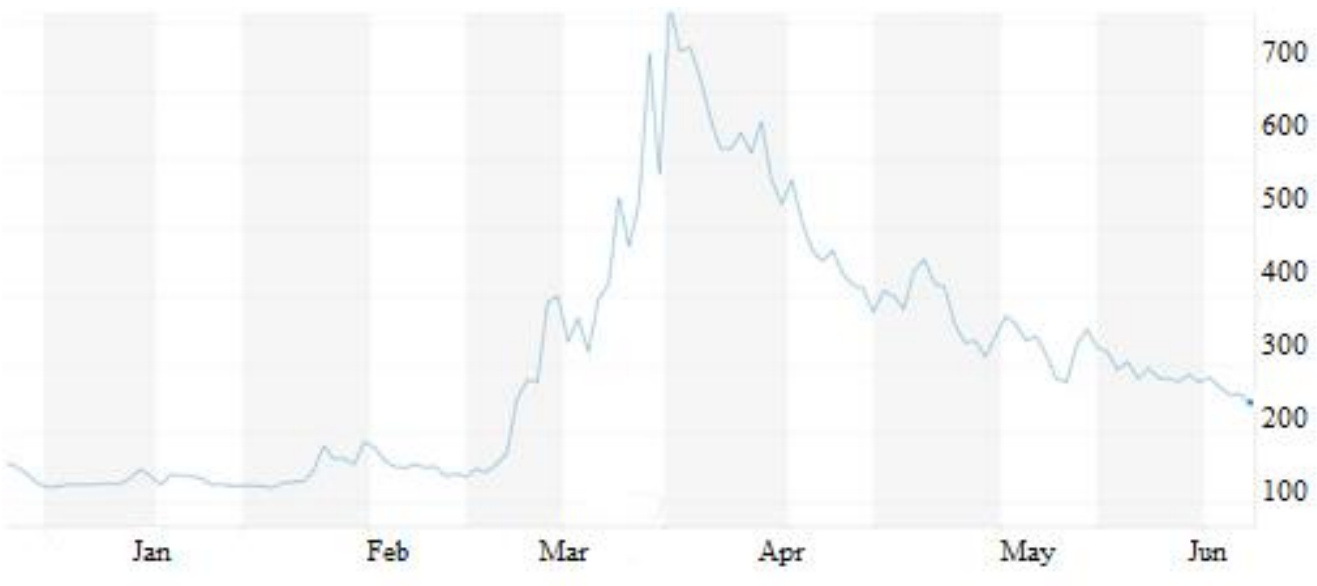

Fig. 2. Index VIX.

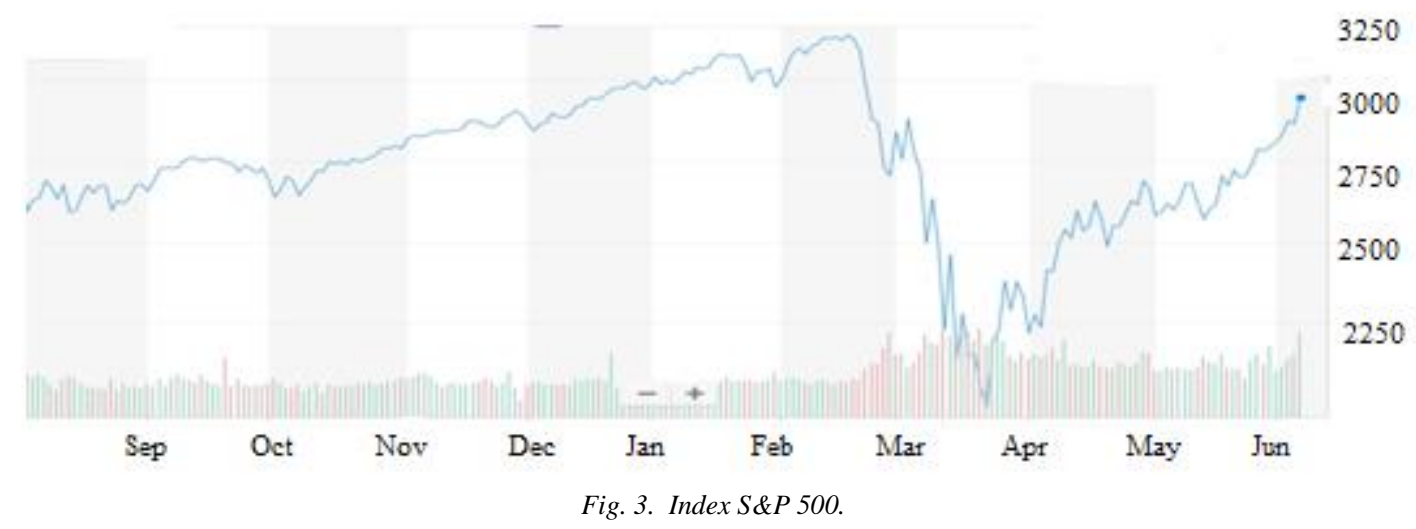

\section{Conclusion}

The current market brings unlimited possibilities in creating an investment strategy. This strategy depends very much on the preferences of the investor, his attitude to risk, financial possibilities, expected return, selfinterest and several other factors that determine what is most suitable for the investor. For this reason, the present work concerns investors who will comply with well-defined restrictions. In this way, an investment strategy for a selected group of investors can be created. After analysing active and passive management, a suitable investment tool was focused on. The investor's profile is only suitable for collective forms of investment due to fees that would cut a significant portion of the invested amount. Here mutual funds with ETF is compared; each of these forms has its own specifics. From the model, which simulated the development of ETF investment and mutual fund, these forms have a different charge burden. In mutual funds, the annual management fee is the most 
expensive. For an ETF, it is an entry into a business that is fixed, which implies that the higher the amount invested, and the longer the deposits, the ETF's profitability increases. The output is also the model itself, which will be publicly available and will help the investors themselves to decide on the choice of investment instrument. A real investor buys when others sell. Now came one of those moments.

The current decline brings an interesting opportunity to invest in equity funds at a significant discount. It is possible that markets will continue to decline. However, waiting for them to reach the bottom is very uncertain. Shares may fall by another $10-30 \%$. With each such decline, it is possible to re-invest.

\section{References}

Abner, D.J. (2010). The ETF handbook: how to value and trade exchange-traded funds. Hoboken, N.J.: Wiley.

Anderson, S.C., Born, J.C. and Schnusenberg, O. (2010). Closed-end funds, exchange-traded funds, and hedge funds: origins, functions, and literature. London: Springer.

Barber, B.M. and Odean, T. (2011). The Behavior of Individual Investors. University of California, Berkeley Haas School of Business.

Boyd, N.E. and MERCER, J.M. (2010). Gains from active bond portfolio management strategies. The Journal of Fixed Income, 19(4).

Broyden, C.G. (1970). The convergence of a class of double-rank minimisation algorithms 2 . The new algorithm. IMA Journal of Applied Mathematics, 6(3).

Byrne, J.P., Fazio, G. and Fiess, N. (2012). Interest rate co-movements, global factors and the long end of the term spread. Journal of Banking \& Finance, 36(1).

Cipra, T. (2013). Financial econometrics. 2. edition. Praha : Ekopress, 2013.

Engelberg, J. and, Sasseville, C. (2009). Market Madness? The Case of Mad Money. 2009.

Evans, R.B. (2009). Mutual Fund Incubation. Journal of Finance, 65(4).

Fama, E.F. and French, K.R. (2007). Dissecting Anomalies. CRSP Working Paper No. 610. Available at SSRN: https://ssrn.com/abstract=911960

Fama, E.F. and FRENCH, K.R. (2009). Luck versus Skill in the Cross Section of Mutual Fund Returns. The Journal of Finance, 65(5).

Ferri, R.A. (2009). The ETF Book: All you need to know about ETFs. New Jersey: Wiley.

Fridson, M. and Alvarez, F. (2002). Financial Statement Analysis: A Practitioner's Guide. 3rd edition. New York: John Wiley \& Sons, Inc.

Faust, J., Rogers, J.H., Swanson, E. and Wright, J.H. (2003). Identifying the effects of monetary policy shocks on exchange rates using high frequency data. Journal of the European Economic association, 1(5).

Hall, A.D. (2010). Getting Started In Mutual Funds. Hoboken: John Wiley \& Sons, Inc.

Haslem, J.A. (2010). Mutual Funds: Portfolio Structures, Analysis, Management, and Stewardship. Hoboken: John Wiley \& Sons, Inc.

Hamilton, J.D. and Wu, J.C. (2012). The effectiveness of alternative monetary policy tools in a zero lower bound environment. Journal of Money, Credit and Banking, 44(s1).

Laurent, D. (2008). Exchange Traded Funds: History, Trading and Research. Handbook of Financial Engineering, Springer.

Lerman, D. (2001). Exchange traded funds and e-mini stock index futures. New York: John Wiley, 2001.

Marfatia, H.A. (2014). Impact of uncertainty on high-frequency response of the US stock markets to the Fed's policy surprises. The Quarterly Review of Economics and Finance, 54(3).

Marfatia, H.A. (2015). Monetary policy's time-varying impact on the US bond markets: Role of financial stress and risks. The North American Journal of Economics and Finance, 34

Marsh (2020). Mining. Available on the internet: https://www.marsh.com/sk/sk/industries/mining.html (accessed 8 March 2020)

Paiardini, P. (2014). The impact of economic news on bond prices: Evidence from the MTS platform. Journal of Banking \& Finance, 49.

Sarwag, G. and Khan, W. (2017). The effect of US stock market uncertainty on emerging market returns. Emerging Markets Finance and Trade, 53(8).

Von Hagen, J., Schuknecht, L., and Wolswijk, G. (2011). Government bond risk premiums in the EU revisited: The impact of the financial crisis. European Journal of Political Economy, 27(1).

Wong, B.K., Bodnovich, T.A. and Selvi, Y. (1997). Neural network applications in business: A review and analysis of the literature (1988-1995). Decision Support Systems, 19(4).

Wright, J.H. (2012). What does monetary policy do to long-term interest rates at the zero lower bound? The Economic Journal, 122(564).

Zhang, X., Li, C. and Morimoto, Y. (2019). A Multi-factor Approach for Stock Price Prediction by using Recurrent Neural Networks. Bulletin of Networking, Computing, Systems, and Software, 8(1). 